\title{
Using renewable energy to create comfort in the first Romanian passive house suited for offices
}

\author{
Gabriel Ivan ${ }^{1, *}$, Ruxandra Crutescu ${ }^{2}$, Claudia $\operatorname{Ivan}^{2}$, and Nicolae Ivan ${ }^{1}$ \\ 1 Technical University of Civil Engineering Bucharest, Bd. Lacul Tei nr. 122 - 124, cod 020396, sector 2, Bucharest, Romania \\ 2 Passivhaus EcoArchitect Bragadiru, Romania
}

\begin{abstract}
Using renewable energy is becoming more profitable nowadays because of applying advanced technology. The paper, presented by the authors, analyses the case of using solar and geothermal energy to create comfort in homes with low energy consumption. In this situation, the performance of the systems that take energy from low-heat renewable sources and convert it into useful energy is growing. The characteristics of the buildings with low power consumption, of passive houses in particular, can cause the development of a new generation of devices to create comfort. The energy used to create comfort in the first passive house built in Romania, which was designed for offices, analyzed by the authors, is using both geothermal and solar power. The authors present the energy performance of the building correlated with the performance of the air-conditioning system that uses ground-water heat pumps. The thermodynamic analysis presented, highlights how the performance of geothermal energy systems increased, their variation depending on the climate zone variation parameter values. The authors make a detailed analysis, in the presented paper, about the influence of the working conditions of the installation elements, on the heat pump energy consumption and the methods adopted to reduce losses and increase system performance.
\end{abstract}

\section{Introduction}

In the beginning, the passive houses were designed with residential purpose. Afterwards, the houses were built as offices; an example is the Bragadiru house built by AMVIC, Romania. For clarity, with regards the above mentioned, a passive house is a building in which the temperature is being kept at a comfortable level both in winter and in summer without any need for a heater.

The characteristics of the passive houses, which are very low energy consumers, require the usage of specific equipment. The energy demand in the buildings has been strongly reduced and most traditional heating systems are oversized for such needs [1]. A passive house requires less heating energy than $15 \mathrm{kWh} / \mathrm{m}^{2}$ per year and its consumption includes hot water and electricity, which does not exceed $120 \mathrm{kWh} / \mathrm{m}^{2}$ year [2]. Renewable energy sources, such as solar energy or thermal energy accumulated in the soil, are well suited for being implemented in these types of houses. Consequently, the exchangers designed to extract heat from the ground are of particular interest in this context. The temperature level inside the house is bound to limits of comfort [3]. Most Europeans find $17-23{ }^{\circ} \mathrm{C}$ comfortable. Low radiation heating in floors and walls is based on a constant temperature of $17-19{ }^{\circ} \mathrm{C}$ in the living area. Although there is an option of using a gap of air temperature of $t=3{ }^{\circ} \mathrm{C}$ to

\footnotetext{
* e-mail: mgvivan@yahoo.com
}

heat up or cool down the house. Primary energy power consumption in passive houses, both in residential and especially non-residential buildings, is much lower than the consumption of heating energy in ordinary houses.

Therefore powers saving technologies are very interesting in all areas of consumption, most of all in buildings that need to be cooled and heated simultaneously [4].

\section{Building description and technical data}

The administrative building is situated inside the production campus of the company. It is of rectangular shape, with an outside stairwell that is a third of the total length, on the south surface.

The building is developed on five levels, the first four as "open space" with administrative purposes (showroom, offices) and a residential attic (residential apartment, guest's rooms, ancillary areas). The main access is on the south facade, through a vestibule (wind fang) and an enclosed stairwell, the access to each level being achieved through insulating doors. Figure 1 presents an exterior view of building and a view from inside the ground floor, opposite to the main access.

The foundation, presented in Figure 2, are continuous, made of reinforced concrete, covered with of extruded polystyrene insulation measuring $20 \mathrm{~cm}$ thickness, over the entire surface, both on the exterior and interior parts, which is applied over a vapor barrier foil with alveoli. 




a)

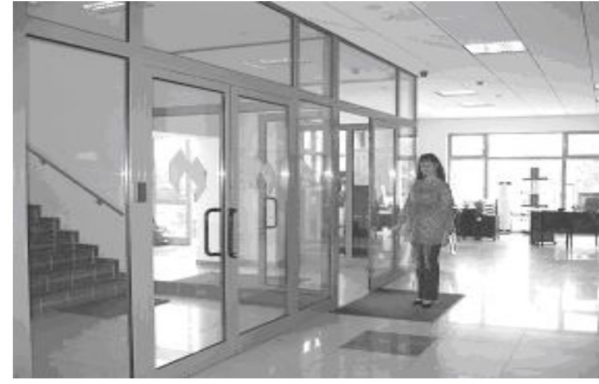

b)

Fig. 1. The passive office building. (a) Outside view, (b) ground floor inner view.

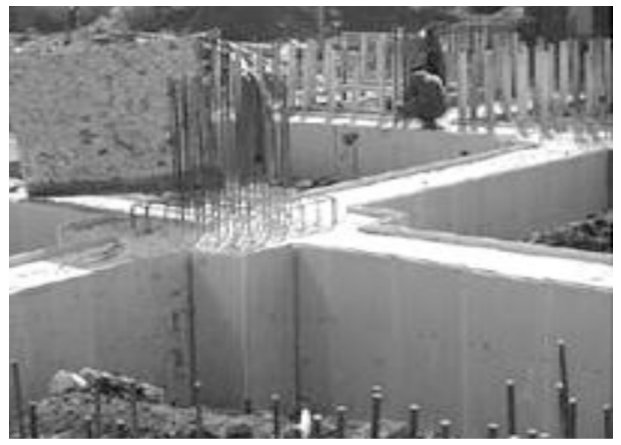

Fig. 2. The building's foundation.

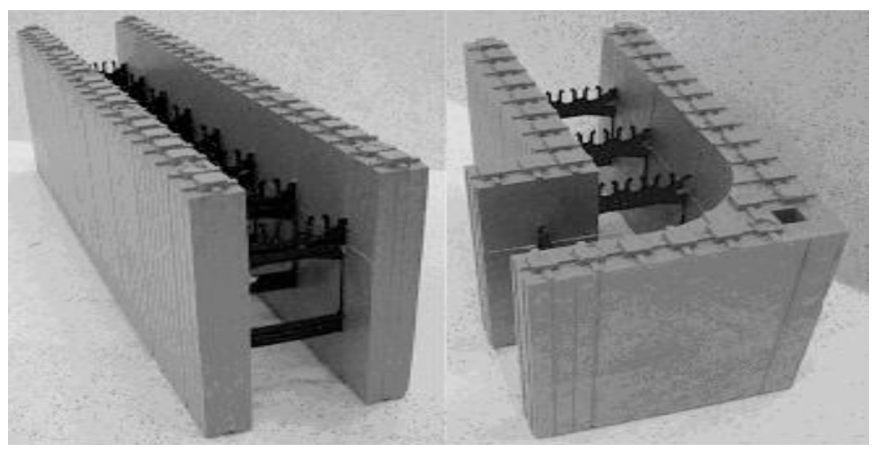

Fig. 3. The permanent thermo insulated casing.

The exterior walls are made out of $20 \mathrm{~cm}$ thick reinforced concrete, cast in a permanent insulated formwork made of $6.3 \mathrm{~cm}$ thick "neopor" (Fig. 3). The exterior was provided an additional insulation of polystyrene foam with the thickness of $20 \mathrm{~cm}$ and a density of $25 \mathrm{~kg} / \mathrm{m}^{3}$, finished with plaster made of adhesive putty with added resin, a fiberglass mesh and decorative paint [5]. The interior walls have an extra cellulose-based (THERMOFLOC) insulation of $7 \mathrm{~cm}$ thickness and a density of $60 \mathrm{~kg} /$ $\mathrm{m}^{3}$, on which a metal structure is mounted, as false wall plasterboard with a thickness of $1.2 \mathrm{~cm}$, finished with decorative paint. Floors are poured of reinforced concrete with ribs. They have a thickness of $33 \mathrm{~cm}$, of which $25 \mathrm{~cm}$ polystyrene foam with a density of $25 \mathrm{~kg} / \mathrm{m}^{3}$, and the ribs, all made of reinforced concrete, having a size of $18 \times 25 \mathrm{~cm}$. The floor finish is made of anti-slip tiles.

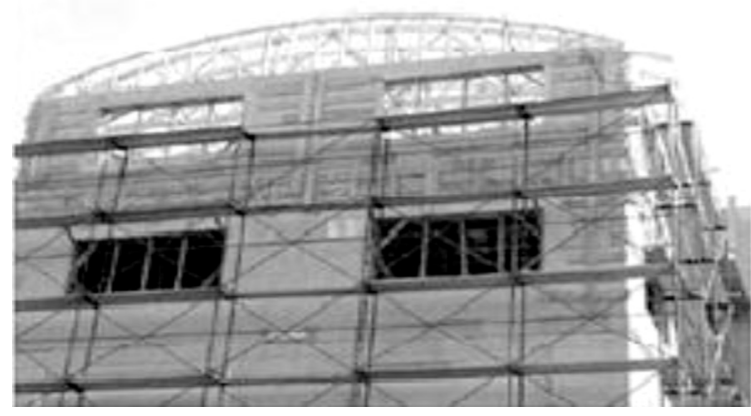

Fig. 4. The remote control shutters.

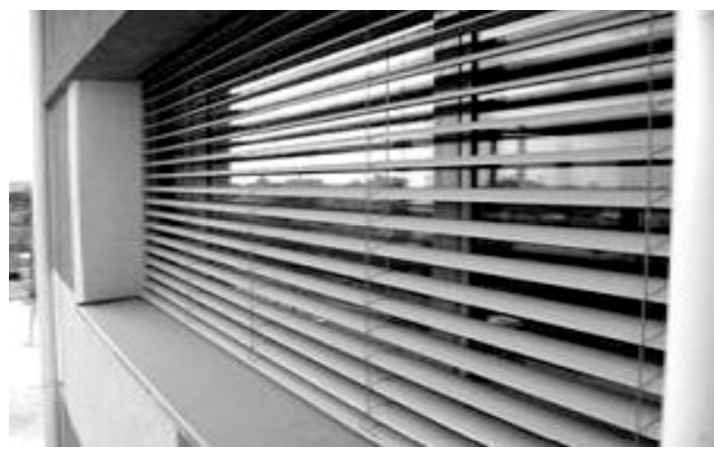

Fig. 5. The roof's framework during construction.

The interior space is divided with walls made of lightweight double plated plasterboard, with a total thickness of $12 \mathrm{~cm}$, with mineral wool insulation of a density of $60 \mathrm{~kg} / \mathrm{m}^{3}$.

External joinery is made of Reynaers class 1.0 aluminum profiles, with insulating glass units with three sheets of glass including two with "low-emission" having krypton between them.

All the exterior glazing on the south and west sides of the building, were provided external servo-operated curtain systems (Fig. 4), which modifies the light intensity, the degree of sunlight and the brightness desired depending on weather conditions. The roof of this building is of fireproof wood sloping type (Fig. 5), with flame retardant cellulose insulation with a thickness of $60 \mathrm{~cm}$ and covered with Lindab profiled sheeting. 


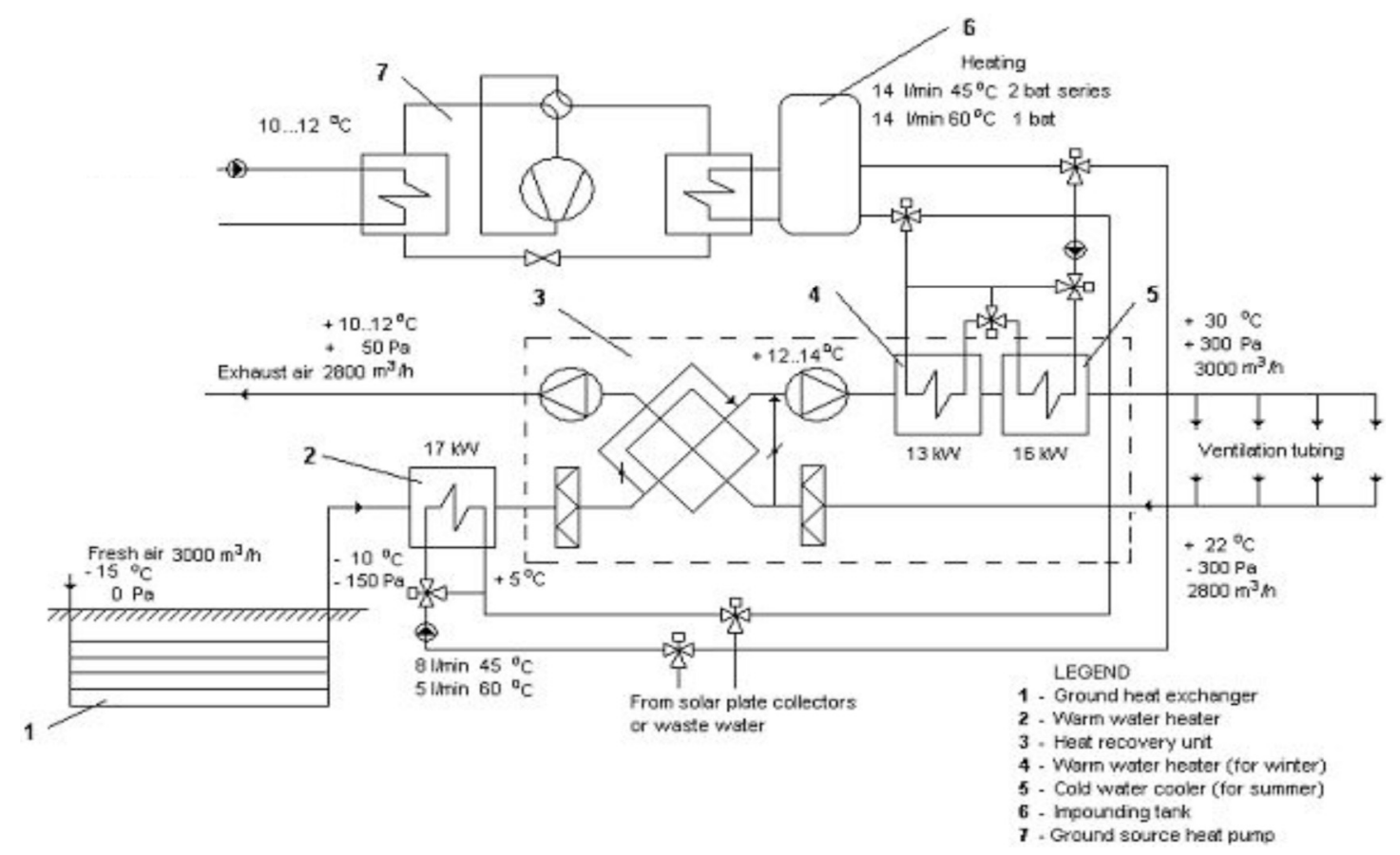

Fig. 6. The building's HVAC system.

The stairwell is made in the same system as the rest of the construction, with structural walls of concrete poured into Neopor insulated formworks, with extruded polystyrene insulation thickness of $20 \mathrm{~cm}$ below the base plate and $20 \mathrm{~cm}$ of additional expanded polystyrene insulation with density $25 \mathrm{~kg} / \mathrm{m}^{3}$ on all exterior walls.

The energy demand for air conditioning and for hot water preparation is provided from renewable energy sources. The schematic diagram of the building's HVAC system is presented in Figure 6. The air needed for ventilation that already provides heating in winter and cooling in summer is taken from the outside through a heat exchanger placed in the soil.

Before being introduced into the building, the fresh air is passed through a heat exchanger where it gets hot in winter and cool in summer from the air extracted from the building and a series of heating-cooling batteries. The heating agent required for these batteries is prepared with the help of a battery of solar collectors, or by using a heat pump that uses the ground as heating source. The fresh air input pipe is made out of ALP sized to carry airflow of $3000 \mathrm{~m}^{3} / \mathrm{h}$ with an average speed of $3 \mathrm{~m} / \mathrm{s}$. For the volume of approx. $7500 \mathrm{~m}^{3}$ of the building this flow corresponds to 0.4 air exchanges per hour. The entry route is developed vertically. From this route, horizontal paths separate on each floor, following the building's length. The piping is installed in plenum (below the floor ceiling), being masked by the plasterboard ceiling. The air introduction diffusers are located only in show rooms, offices or living rooms. The direction of the air jet can be adjusted in two ways. This feature will ensure the comfort of the room occupants. The air circulates into open spaces and then moves in the annex rooms (bathrooms, closets offices) through a series of transfer grids placed on based door. Hence, indoor air is pulled out through the circular, transfer grilles which are placed in the false ceiling. Two vertical columns that come together in the ground floor, just before entering the heat recovery exchanger, take the evacuated flow. Ground-air heat exchanger (GAHE) is made out of equidistant horizontal polypropylene tubes. It is a REHAU AWADUKT system with an external diameter of $200 \mathrm{~mm}$. These tubes are caught between collectors with an external diameter of $400 \mathrm{~mm}$. It is buried at a depth of $3.5 \mathrm{~m}$ in the orchard adjoining the west side of the building.

The dimensions were determined in relation to available land, for laying the distance between the pipes being determined by the distance between the rows of trees, their length and the length of the land. Fresh air aspiration is performed through a vertical inlet [1]. The inlet is provided with weather protection and an air filter.

The solar system that provides the consumption of hot water consists of an intake area of $20 \mathrm{~m}^{2}$ with vacuum tubes placed on the roof, and a $300 \mathrm{l}$ storage tank placed in building's attic.

The tank is provided with a heating electrical resistance to ensure hot water supply even in situations when solar energy cannot be captured. The solar heating system for the fresh air blown into the building consists of an intake area of $180 \mathrm{~m}^{2}$ with vacuum tubes and a storage tank of $3000 \mathrm{l}$. This storage tank is the heat source for air conditioning unit heating batteries.

During cold seasons, the solar energy captured by the system provides about $65 \%$ of hot water needed for consumption and approx. $60 \%$ of battery required for heating fresh air. To cover the heat demand of the air heater batteries in peak periods or in situations where it cannot capture solar energy (night, overcast, etc.), a "ground-water" heat pump type can be used, having soil as a heat source. The wasted hot water from the polystyrene plant can also be used, when available, as heating source for fresh air heating batteries. 


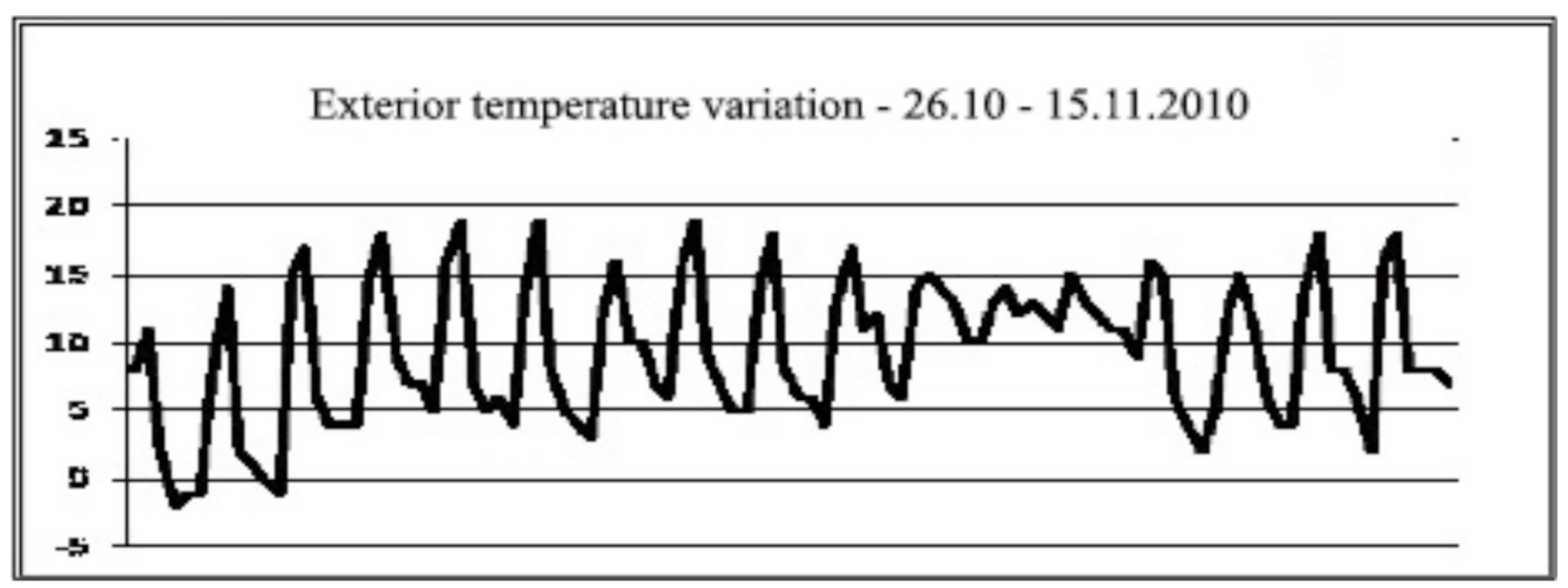

Fig. 7. Exterior temperature variations.
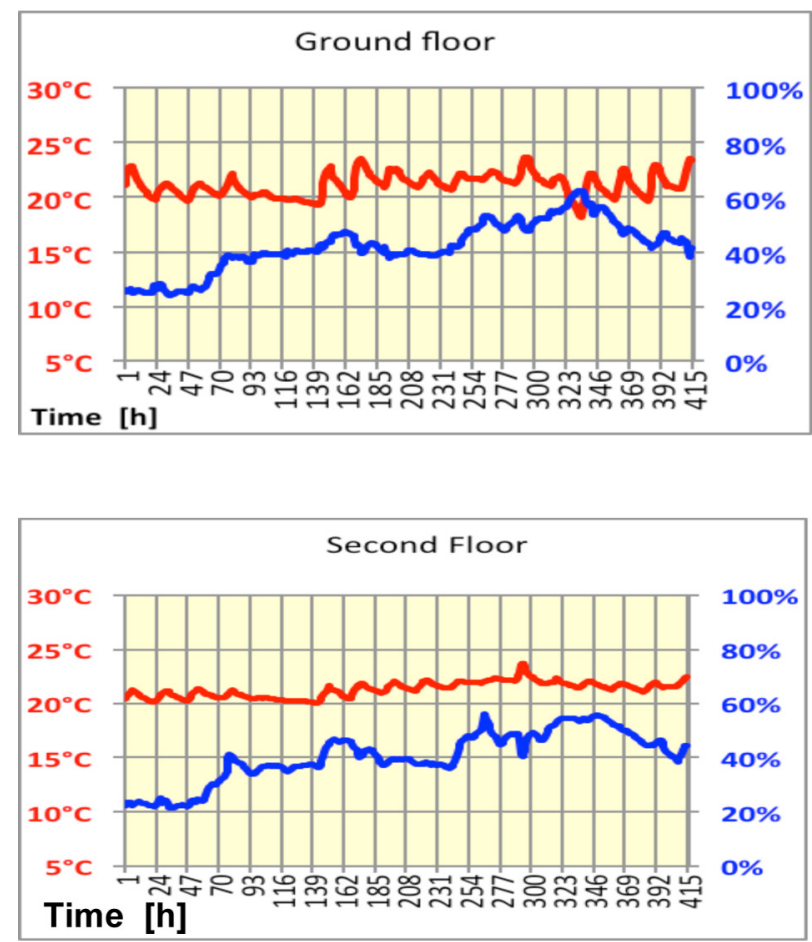

Interior measured temperature
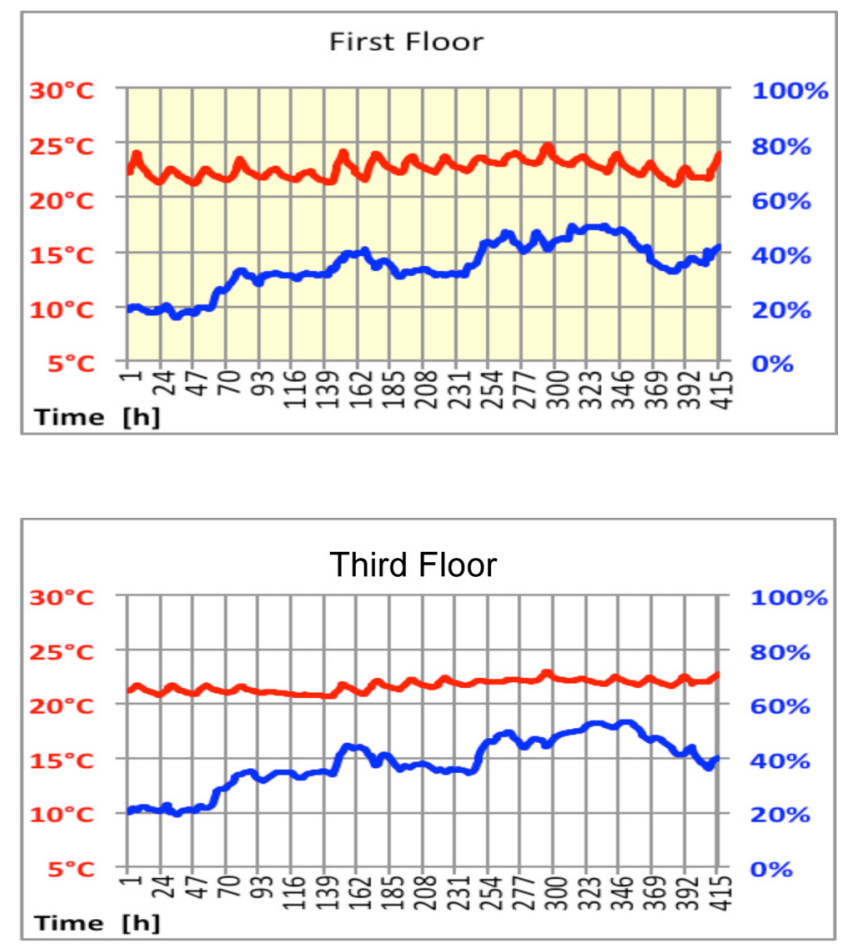

Interior measured humidity

Fig. 8. Interior temperature and humidity evolution.

\section{Measurement results}

By monitoring the temperature, humidity and electrical consumption, the real specific energy consumption of the building can be determined. The average thermal resistance of the building, according to the mentioned structure, is $6.94 \mathrm{~m}^{2} \mathrm{~K} / \mathrm{W}$, which leads to a specific heating energy consumption of $9.56 \mathrm{kWh} / \mathrm{m}^{2}$ year, less than $15 \mathrm{kWh} /$ $\mathrm{m}^{2}$ year. These results describe a very good insulated envelope and the high quality of the glasses.

In order to monitor an optimal function and to establish energy indicators, the building was equipped with sensors and systems to measure and record the external and internal climate parameters. These parameters are used to determine the energy consumption from renewable sources and electricity consumption. All information generated by sensors is taken online, and they can be seen in real time and stored in a database.

In Figures 7 and 8 the variation of the temperature and humidity can be observed, both for the exterior as well as the interior of the building during the analyzed period.

Specific energy consumptions of the building for hot water preparation, lighting and ventilation were determined based on the characteristics of consumers and the building-operating mode. These specific consumptions are as follows:

- specific consumption energy for lighting: $q_{1}=14.46$ $\mathrm{kWh} / \mathrm{m}^{2}$ year; 


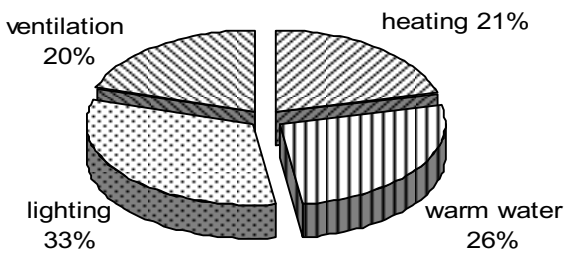

Fig. 9. The energy percentage used for creating thermal comfort and lighting.

- specific consumption energy for ventilation: $q_{\mathrm{v}}=9.07$ $\mathrm{kWh} / \mathrm{m}^{2}$ year;

- specific consumption energy for domestic hot water: $q_{\mathrm{dhw}}=11.86 \mathrm{kWh} / \mathrm{m}^{2}$ year.

This specific consumption was determined using corrected thermal resistance of the envelope containing opaque and transparent parts.

The energetically balance of the building highlights that heating and ventilation are $41 \%$ of the entire consumption. The heat pump is used in both processes. During certain periods, the ground-water heat pump covers the entire heat demand of the building.

The warm water was prepared using solar energy. Only during the cold period electrical energy will be necessary to heat up water. The reversible ground-water heat pump has two drills, each one having two exchangers (four pipes). These pipes were drilled at depth of $120 \mathrm{~m}$.

In the next image (Fig. 9) can be observed the percentages of the energy used in order to create the optimal comfort, thermal and electrical energy. The energy used for heating was gained from soil and sun. Waste hot water obtained from an industrial process has also played a crucial role in order to obtain this free energy.

\section{Conclusion}

Looking at the already measured parameters and the calculated thermal power, we can highlight the fact that the share of renewable energy in the balance is approx. $40 \%$. The heat pump covers $21 \%$ of the heating needs. The warm water energy is gained $26 \%$ from solar energy during summer time.

Nevertheless these complex systems allow the usage of heat pumps and solar panels during their maximum performance period. Thermal performances of the heat pumps and solar panels depend on the exploitation conditions. In this way, as mentioned above, the energy taken from renewable energy sources could be considered of great importance.

\section{References}

1. G. Ivan, N. Ivan, D. Isvoranu, V. Badescu, Heat exchangers for passive houses, in The 3rd Thermal Engines and Environmental Engineering Conference, METIME, Galati, Romania (2009)

2. B.S. Darup, A vision becomes a standard, in 12th International Conference on Passive Houses 2008, Nuremberg, Germany (2008)

3. C. Marza, G. Corsiuc, Concepte de realizare a cladirilor avand consum energetic redus, in Conferinta Stiinta Moderna si Energia, Editia 33, Cluj-Napoca 2014, Romania (2014)

4. B. Todorovic, Towards zero energy buildings: new and retrofitted existing buildings - examples around the world, in Instalatii pentru inceputul mileniului trei, Vol II, A 46-a, Conferinta Nationala de Instalatii, Sinaia 19-21 oct. 2011, Romania (2011)

5. G. Ivan, R. Crutescu, S. Dimitriu, M. Crutescu, N. Ivan, The first Romanian passive office building, in Congrès CLIMA 2010, Antalya, 9-12 May 2010 (2010)

Cite this article as: Gabriel Ivan, Ruxandra Crutescu, Claudia Ivan, Nicolae Ivan, Using renewable energy to create comfort in the first Romanian passive house suited for offices, Renew. Energy Environ. Sustain. 1, 11 (2016) 